\title{
Corrigendum
}

\section{Chloride Channel CICN7 Mutations in a Korean Patient with Infantile Malignant Osteopetrosis Initially Presenting with Neonatal Thrombocytopenia}

Youn-Jeong Shin, MD

So Eun Park, MD

Ghyu Hong Shim, MD

Jin A Lee, MD

Ee Kyung Kim, MD

Jun Dong Park, MD

Beyong IL Kim, MD

Jung Hwan Choi, MD, PhD

Annalisa Frattini, PhD
Journal of Perinatology (2004) 24, 610. doi:10.1038/sj.jp.7211162

Correction to: Journal of Perinatology (2004) 24, 312-314. doi:10.1038/jp.7211081

Following publication of the above paper, the author has identified that the complete listing of contributing authors' names was originally missing. Their names are now all listed above. 